\section{Military Technical College \\ Kobry El-Kobbah, \\ Cairo, Egypt.}

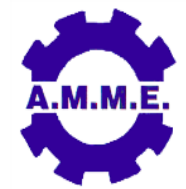

\title{
PREDICTION OF ABRASIVE WATER JET CUTTING PARAMETERS USING ARTIFICIAL NEURAL NETWORK
}

\author{
Y. M. Elattar ${ }^{1}$, M. A. Mahdy ${ }^{2}$ and H. A. Sonbol $\left.\right|^{3}$
}

\begin{abstract}
This work presents a new predictive model of abrasive water-jet (AWJ) machining of ARMOX shielding steel plate of $7.6 \mathrm{~mm}$ thick. The model was developed to predict some interesting process parameters from process variables. As AWJ is a complicated multi input multi output machining process. The model is developed using artificial neural network (ANN). A feed forward neural network based on back propagation was made up of 4 input neurons, 1 hidden layer with 10 hidden neurons and 2 output neurons. The ANN training set was generated by extensive experimental work. The tests considered four process variables. The studied AWJ process variables are traverse speed $(T)$, waterjet pressure $(P)$, standoff distance $(\mathrm{s})$, and abrasive flow rate $\left(m_{a}\right)$. The considered process parameters are surface roughness $\left(R_{a}\right)$ and material removal rate (MRR). The ANN model was trained and tested. The ANN succeeded to model the AWJ process by extracting the process parameters from process variables with a regression factor above $90 \%$. This paper is a step forward to model and control the AWJ machining process.
\end{abstract}

\section{KEYWORDS}

Abrasive water jet (AWJ), Armox, artificial neural network (ANN), surface roughness $(\mathrm{Ra})$, material removal rate (MRR)

Assistant Lecturer, Modern Academy for Engineering and Tech., Cairo, Egypt.

Dean of Higher Institute for Engineering and Modern Technology Marg, Cairo, Egypt.

Professor, Design and Prod. Eng. Dept., Faculty of Engineering, Ain Shams University, Cairo, Egypt. 


\section{NOMENCLATURE}

$\begin{array}{ll}\text { ANN } & \text { Artificial neural network } \\ \text { AWJ } & \text { Abrasive water jet } \\ \mathrm{m}_{\mathrm{a}} & \text { Abrasive flow rate }(\mathrm{g} / \mathrm{min}) \\ \mathrm{MRR} & \text { Material removal rate }\left(\mathrm{cm}^{3} / \mathrm{min}\right) \\ \mathrm{P} & \text { Waterjet pressure }(\mathrm{MPa}) \\ \mathrm{R}_{\mathrm{a}} & \text { Surface roughness }(\mu \mathrm{m}) \\ \mathrm{s} & \text { Stand-off distance }(\mathrm{mm}) \\ \mathrm{T} & \text { Traverse speed }(\mathrm{mm} / \mathrm{min}) \\ \mathrm{t} & \text { Machining time }(\mathrm{min}) \\ \mathrm{W}_{\mathrm{f}} & \text { Final weight of specimen after machining }(\mathrm{g}) \\ \mathrm{W}_{\mathrm{i}} & \text { Initial weight of specimen }(\mathrm{g}) \\ \rho & \text { Density of Armox }\left(\mathrm{g} / \mathrm{cm}^{3}\right) .\end{array}$

\section{INTRODUCTION}

\section{Abrasive Water Jet (AWJ)}

High-pressure water jets have been in continuous development since the beginning of the 20th century. Amongst all the machining techniques, abrasive water jet (AWJ) has the advantage of achieving the same quality of cut without any micro-cracking and thermal weakening when compared to other processes. The AWJ process can virtually cut through any material (most suited for hard and brittle materials) with a relatively lower machining cost. The key is the abrasive materials that are contained in the jet of water for the process [1-2].

The use of the abrasive water jet for machining or finishing purposes is based on the principle of erosion of the material upon which the jet hits. The purpose of the abrasive material within the jet stream to provide the erosive forces. The jet delivers the abrasive material to the workpiece for the purpose of erosion. However, the jet also accelerates the abrasive material to a speed such that the impact and change in momentum of the abrasive material can aid it in performing its function. In addition, the water carries both the abrasive material and the eroded material clear of the work area so that additional processing can be performed [3].

Determining the optimal process parameters by testing / experimentation is a time consuming and cost ineffective procedure. The knowledge of a mathematical function that relates the cutting parameters to the cutting results is necessary for a computer controlled cutting process. An important aspect is to estimate some of the most crucial

output process parameters using the input variables. The main operating variables influencing the AWJ cutting process variables are traverse speed $(T)$, waterjet pressure $(P)$, standoff distance $(s)$, and abrasive flow rate $\left(m_{a}\right)$ (Fig. 1) [4].

\section{Artificial Neural Network (ANN)}

ANN is an empirical machine learning strategy. It is appealing to a wide range of 


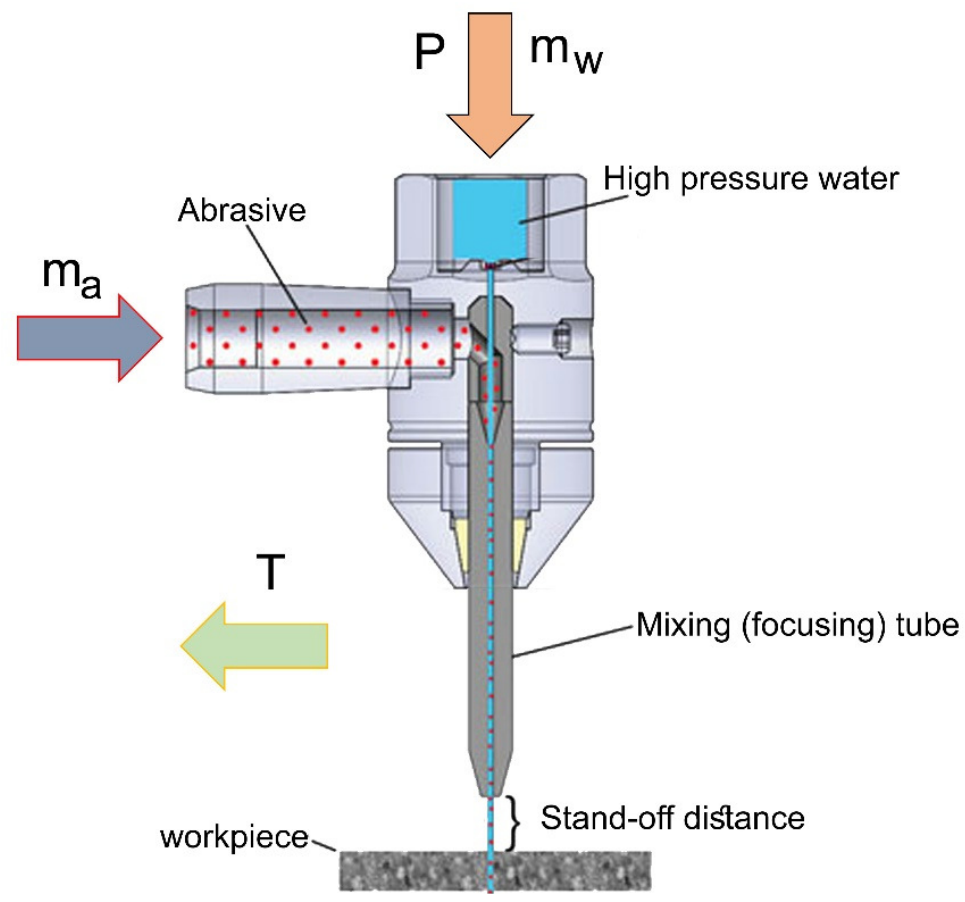

Fig. 1. Schematic of abrasive water jet machining process.

applications, which include functional approximation, pattern recognition, time series forecasting and others [5].

The computation in ANN model is distributed over simple several units called neurons which are interconnected and operated in parallel. Hence, it is a simple, rapid and accurate model. The ability of ANN to learn from examples makes it efficient problem-solving patterns. Moreover, ANN possesses some obvious advantageous features such like:

a) The ability to recognize and learn the underlying relations between inputs and outputs without explicit physical consideration and regardless of the problem dimensionality and system nonlinearity.

b) The high tolerance to data containing noise and measurement errors due to distributed processing within the network.

c) Multidisciplinary nature providing popularities among researchers, planners, and designers.

d) Shows a good performance in the solving of non-linear multivariable problems.

e) Continuously re-train the new data meaning that it can conveniently be applied to new data.

f) Does not need any assumption for the degree of nonlinearity among the variables.

Therefore, in recent twenty years, ANN is becoming popular in the research of many science and engineering fields [6,7]. A typical feed-forward neural network structure with back-propagation algorithm as shown in Fig. 2 was adopted in the present study. This technique is most commonly used in many researches [6,7]. And includes multiple layers namely input, hidden and output layers with specific number of neurons, initial weights and biases as well as neuron functions. The neuron in each layer performs two functions, summation and activation functions respectively to sum 
the weighted inputs then squash this summation to produce the output. The information is fed and flows between the neurons in the forward direction where each layer receives signals from one neuron before it and passes its output to another subsequent layer. Back-propagation algorithm was used as a training algorithm for feed forward neural network where it would produce the cumulative network error between its final output and the actual output and this error is back-propagated to adjust the weights values in the whole network mechanism as shown in Fig. 2.

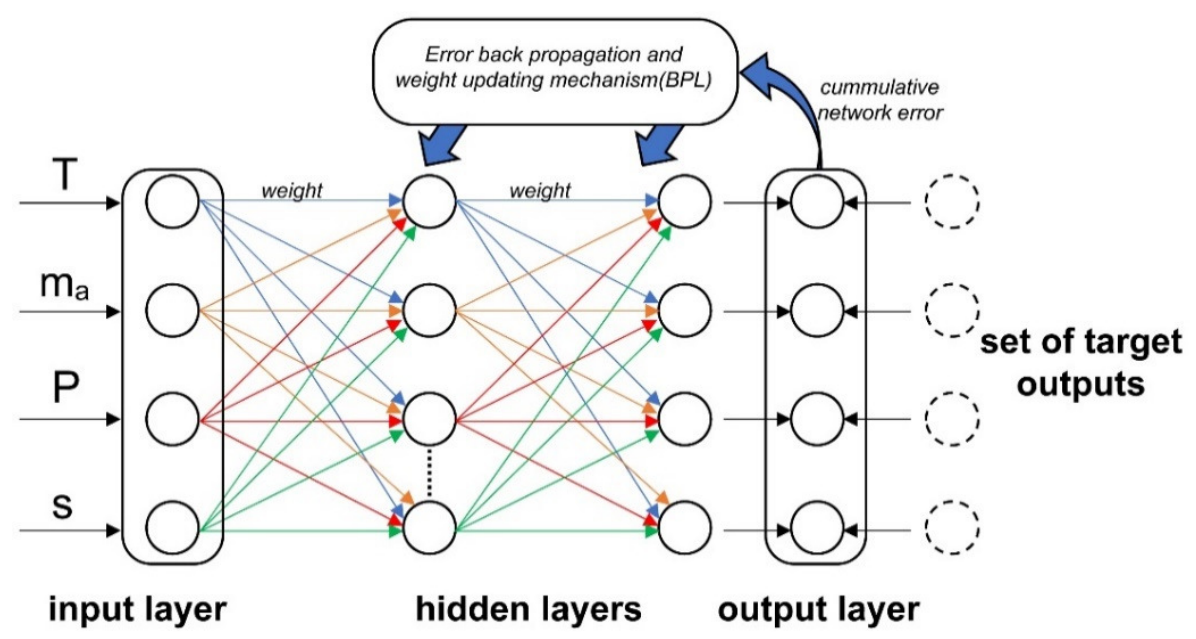

Fig. 2. Multi-layer artificial neural network with a back-propagation algorithm.

One hidden layer was found to be enough in this study and thus the architecture of ANN was a three-layer structure. The parameters for input layer and output layer had been selected as mentioned previously, while the number of neurons in the hidden layer needs to be optimized.

ARMOX is protection steel used in military applications and armored shields. it is commonly used for security patrol vehicles, cash in transit vehicles, military armored vehicles, and in some protected facilities buildings. Armox has high strength, hardness and good toughness. It acquires these specific properties due to its chemical composition and a specific production process, finalized by very rapid quenching and tempering. The chemical purity in combination with very rapid cooling brings good toughness of material despite of tempering at very low temperature [810].

Surface roughness $\left(R_{a}\right)$ and material removal rate (MRR) are considered as a performance criterion and modeled using artificial neural network (ANN) based on process variables. Four operating variables, including traverse speed $(T)$, waterjet pressure $(P)$, standoff distance $(s)$, and abrasive flow rate $\left(m_{a}\right)$, are studied for obtaining different results for the $R_{a}$ and MRR.

Data belonging to the trials are used for construction of ANN. The developed model is then tested using a test data set which is not utilized during construction of the model. As a result, it is concluded that ANN model can give adequate prediction for the $R_{a}$ and MRR with an acceptable accuracy level.

The main objective of the present research is to use the artificial neural network to 
develop a model that is capable to predict the process output parameters from certain process variables. Therefore, experiments in different values of process variables, which influence the process parameters in interest.

\section{EXPERIMENTAL WORK}

\section{Material Selection}

The material used in this study was Armox with a thickness of $7.6 \mathrm{~mm}$. The nominal chemical compositions of the test material are listed in Table 1 and the mechanical properties are shown in Table 2. The experiments were performed on a SOITAAB AWJ machine, Table 3 shows the machine specifications.

Table 1. Chemical composition of ARMOX [11].

\begin{tabular}{|c|c|c|c|c|c|c|c|c|}
\hline $\begin{array}{c}\mathbf{C} \\
(\max \%)\end{array}$ & $\begin{array}{c}\mathrm{Si} \\
(\max \%)\end{array}$ & $\begin{array}{c}\mathrm{Mn} \\
(\max \%)\end{array}$ & $\begin{array}{c}\mathbf{P} \\
(\max \%)\end{array}$ & $\begin{array}{c}\mathrm{S} \\
(\max \%)\end{array}$ & $\begin{array}{c}\mathrm{Cr} \\
(\max \%)\end{array}$ & $\begin{array}{c}\mathrm{Ni} \\
(\max \%)\end{array}$ & $\begin{array}{c}\text { Mo } \\
(\max \%)\end{array}$ & $\begin{array}{c}\mathbf{B} \\
(\max \%)\end{array}$ \\
\hline 0.32 & 0.4 & 1.2 & 0.010 & 0.003 & 1.0 & 1.8 & 0.7 & 0.005 \\
\hline
\end{tabular}

Table 2. Mechanical properties of ARMOX [11].

\begin{tabular}{|c|c|c|c|c|c|c|}
\hline $\begin{array}{c}\text { Young's } \\
\text { modulus, } \\
(\mathrm{GPa})\end{array}$ & $\begin{array}{c}\text { Poisson } \\
\text { coefficient }\end{array}$ & $\begin{array}{c}\text { Density, } \\
\left(\mathrm{Kg} / \mathbf{m}^{3}\right)\end{array}$ & $\begin{array}{c}\text { Yield } \\
\text { strength, } \\
(\mathrm{MPa})\end{array}$ & $\begin{array}{c}\text { Tensile } \\
\text { strength, } \\
(\mathrm{MPa})\end{array}$ & $\begin{array}{c}\text { Elongation, } \\
(\%)\end{array}$ & $\begin{array}{c}\text { Hardness } \\
\text { (HBW) }\end{array}$ \\
\hline 207 & 0.3 & 7850 & 1250 & $1450-1750$ & $8-10$ & $480-540$ \\
\hline
\end{tabular}

Table 3. General specifications of AWJ machine [12].

\begin{tabular}{|l|l|}
\hline Item & Identification \\
\hline Machine model & SOITAAB \\
\hline Nozzle diameter & $1.2 \mathrm{~mm}$ \\
\hline Jet angle & $90^{\circ}$ \\
\hline Max. pressure & $400 \mathrm{MPa}$ \\
\hline Max. flow rate & $520 \mathrm{~g} / \mathrm{min}$ \\
\hline Stand-off distance & More than $1 \mathrm{~mm}$ \\
\hline
\end{tabular}

\section{AWJ Cutting Procedure and Design of Experiments}

In the experimental plan, the most dominant process variables such as traverse speed $(T)$, waterjet pressure $(P)$, standoff distance $(s)$, and abrasive flow rate $\left(m_{a}\right)$ 
were varied. During the experiments, only one process variable is considered at a time while the other variables are fixed.

Data were input to ANN model as a matrix of six columns. The first four columns are traverse speed, waterjet pressure, stand-off distance, and abrasive flow rate. While the second two columns are resulted surface roughness and material removal rate respectively. ANN pattern is adjusted to use $70 \%$ of input data to learn and train, $15 \%$ to validate, and final $15 \%$ to test [20]. So, a set of 50 different experiments were set as an input data for the ANN. Also, another 11 different values of variables were used to test the pattern performance after the ANN model was developed. Table 4 shows sample of data used to learn and test the ANN model. For training MATLAB Version R2014a was used throughout the study.

Table 4. Sample of experimental results.

\begin{tabular}{|c|c|c|c|c|c|c|}
\hline Ex. No. & $\mathbf{T}$ & $\mathbf{P}$ & $\mathbf{s}$ & $\mathbf{m}_{\mathbf{a}}$ & $\mathbf{R}_{\mathbf{a}}$ & $\mathbf{M R R}$ \\
\hline 1 & 1 & 1 & 1 & 1 & $\mathbf{\mu m}$ & $\mathbf{c m}^{\mathbf{3}} \mathbf{m i n}$ \\
\hline 2 & 1 & 2 & 2 & 2 & 3.35 & 0.6435 \\
\hline 3 & 1 & 3 & 3 & 3 & 3.41 & 0.611 \\
\hline 4 & 1 & 4 & 4 & 4 & 4.15 & 3.1447 \\
\hline 5 & 2 & 1 & 2 & 3 & 2.90 & 1.642 \\
\hline 6 & 2 & 2 & 1 & 4 & 3.12 & 1.158 \\
\hline 7 & 2 & 3 & 4 & 1 & 5.79 & 0.7125 \\
\hline 8 & 2 & 4 & 3 & 2 & 5.82 & 1.534 \\
\hline 9 & 3 & 1 & 3 & 4 & 3.43 & 3.633 \\
\hline 10 & 3 & 2 & 4 & 3 & 4.88 & 3.521 \\
\hline
\end{tabular}

\section{MRR and $R_{a}$ Measuring Procedures}

All specimens were prepared to final size before machining. Specimen dimensions were $80 \mathrm{~mm} \times 50 \mathrm{~mm} \times 7.6 \mathrm{~mm}$ and they were deburred and cleaned. MRR was calculated from the difference of weights of specimen before and after experiment. Weights were measured in laboratory using sensitive scale SCALTEC SBA 41 (Fig. 3).

$\operatorname{MRR}=\frac{W_{i}-W_{f}}{\rho t} \mathrm{~cm}^{3} / \mathrm{min}$

where $\mathrm{W}_{\mathrm{i}}$ is the initial weight of specimen in $\mathrm{g}, \mathrm{W}_{\mathrm{f}}$ is the final weight of specimen after machining in $\mathrm{g}$, $\mathrm{t}$ is the machining time in min. and $\rho$ is density of Armox $\left(\mathrm{g} / \mathrm{cm}^{3}\right)$.

After cutting, the surface roughness of the machined surface was measured parallel to the feed direction using TR200 hand-held roughness tester (Fig. 4). Three values of surface roughness for each specimen were measured at the center of the produced surface, and an average value was calculated for each specimen. 


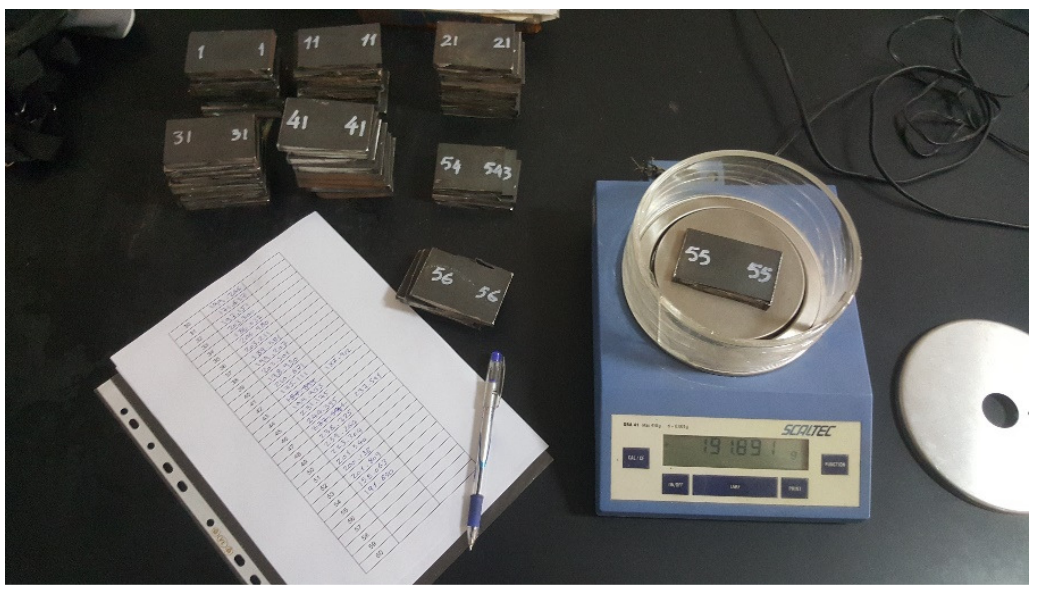

Fig. 3. Measuring weights of specimens in laboratory using SBA 41 sensitive scale.

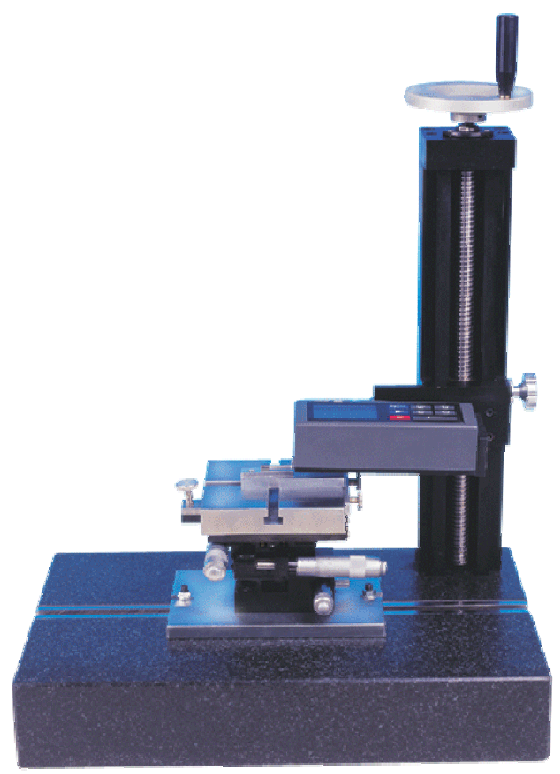

Fig. 4. TR200 roughness tester apparatus.

\section{NETWORK TOPOLOGY, TRAINING AND TESTING}

In this work, back-propagation multi-layer feed-forward neural network algorithm was used for developing ANN model. Before applying the neural network for modeling, the architecture of the network was determined; i.e. number of hidden layers and number of neurons in each hidden layer. The architecture of the network used in this study was a three-layer structure with four neurons at the input layer and two neurons at the output layer as shown in Fig. 5. The general network was supposed to be 4-n-2. The inputs neurons are traverse speed $(T)$, waterjet pressure $(P)$, standoff distance $(\mathrm{s})$, and abrasive flow rate $\left(\mathrm{m}_{\mathrm{a}}\right)$. While the output neurons of the network are surface roughness $\left(R_{a}\right)$ and material removal rate (MRR). 


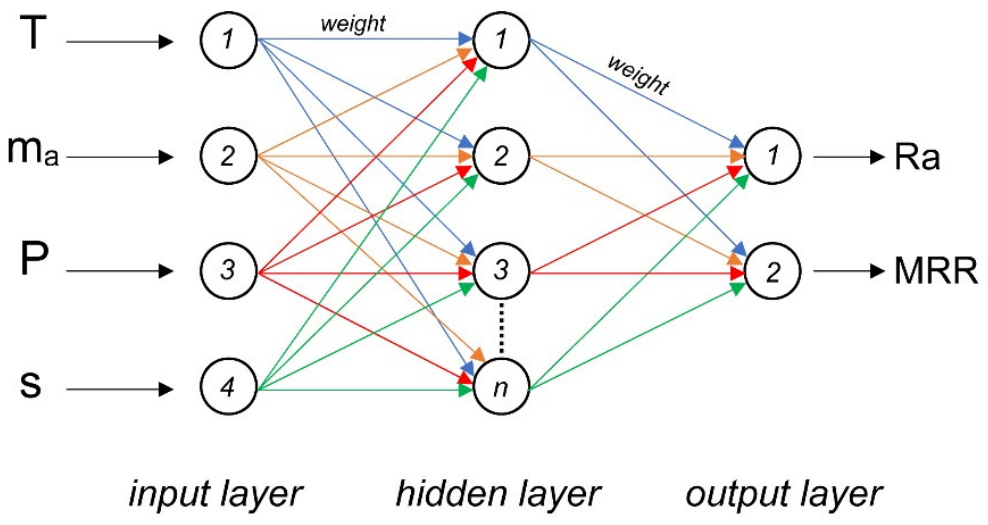

Fig. 5. Architecture of utilized ANN.

Size of hidden layers $(n)$ is the most important considerations when solving actual problems using multi-layer feed forward network [7]. It is noted that back-propagation architecture with one hidden layer is adopted for the majority of applications [13-18]. Hence, only one hidden layer is used in the network.

\section{Optimum Number of Hidden Neurons (N)}

To find the best number of neurons in the hidden layer, experimental and predicted outputs for different number of neurons in the hidden layer were compared. The prediction error, the average prediction error and the total average prediction error between experimental and predicted outputs were calculated as:

Prediction error $\%=\left|\frac{\text { Predicted result }- \text { Experimental result }}{\text { Experimental result }}\right|$

Average prediction error $\%=\frac{\sum_{\mathrm{i}=1}^{\mathrm{n}} \text { prediction error } \%}{\mathrm{n}}$

Total average prediction error $\%=\frac{\sum_{i=1}^{m} \text { Average prediction error } \%}{m}$

where $n$ is the number of verifications experiments and $m$ is the number of experimental responses, i.e. MRR and $\mathrm{R}_{\mathrm{a}}$.

The average prediction error between experimental and predicted results was calculated and plotted against the number of neurons in the hidden layer as shown in Fig. 6. It was observed that this average prediction error was minimized at 10 neurons.

\section{Optimum Number of Epochs}

Iteration number versus mean square error (MSE) is shown in Fig. 7. It can be seen 


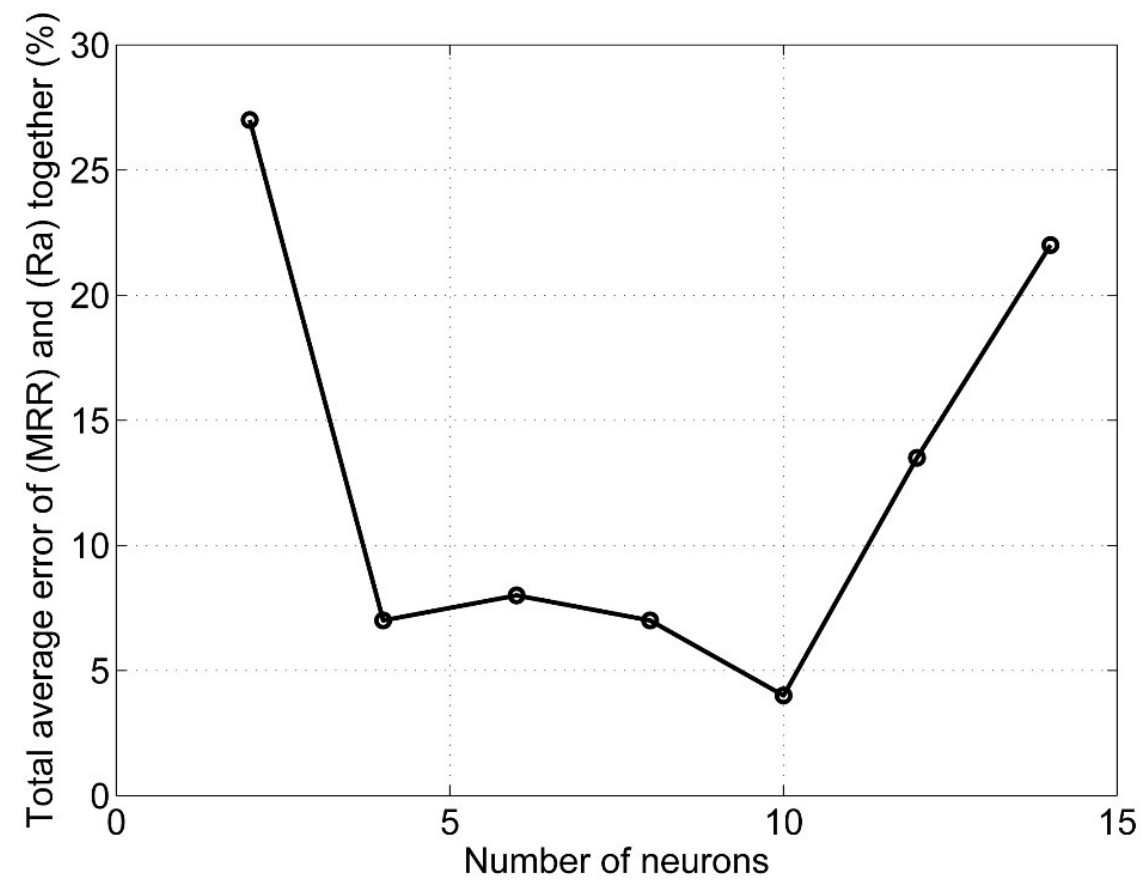

Fig. 6. Total average error of (MRR) and $\left(R_{a}\right)$ together $(\%)$ vs Number of hidden neurons.

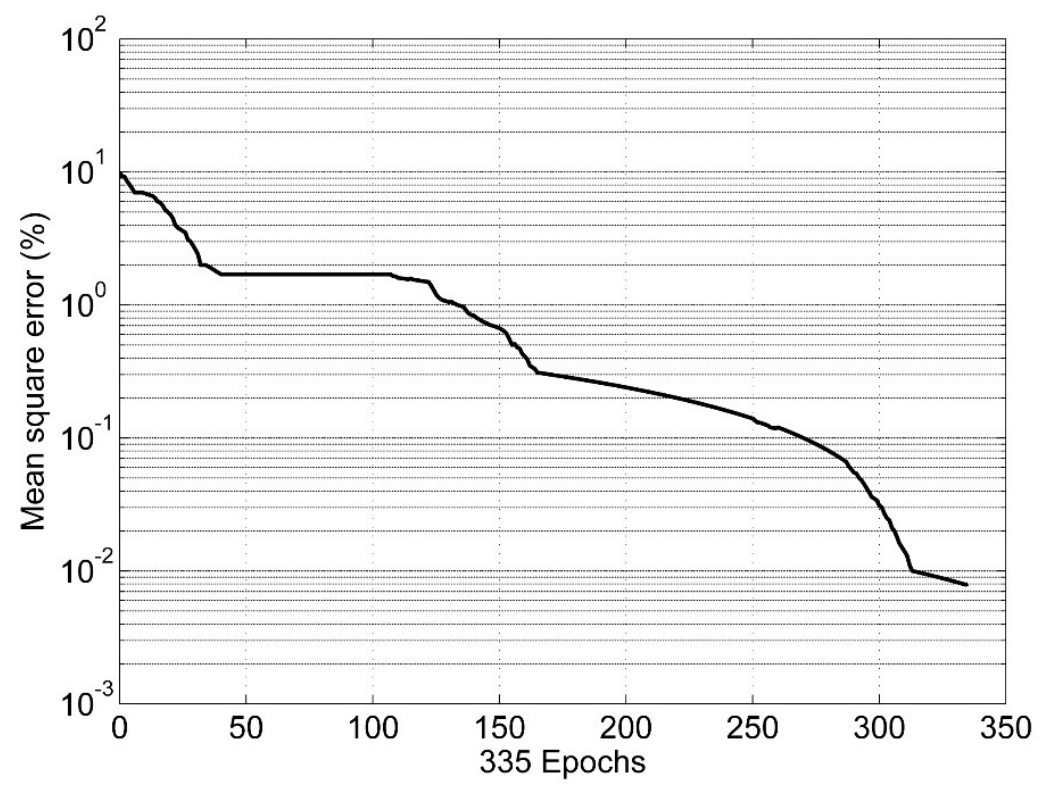

Fig. 7. Iteration number (Epochs) vs. mean square error (MSE).

that training of ANN can be achieved quickly. After 335 cycles of training (Epochs), the training error of network reaches stabilization value. The mean error is 0.007 . The error is lower than $10 \%$, which show that the well-trained network model takes on optimal performance and has a great accuracy in predicting surface roughness [19]. 


\section{Regression Plot of the ANN}

It was also found that the performance of the developed ANN technique in predicting the values of MRR and $R_{a}$ was satisfactory due to higher values of regression between the targets and outputs during training, testing and validation for the proposed ANN model as shown in Fig. 8. This regression plot indicated the higher performance of the ANN in predicting responses for any new input data.

Training: $\mathrm{R}=0.98011$

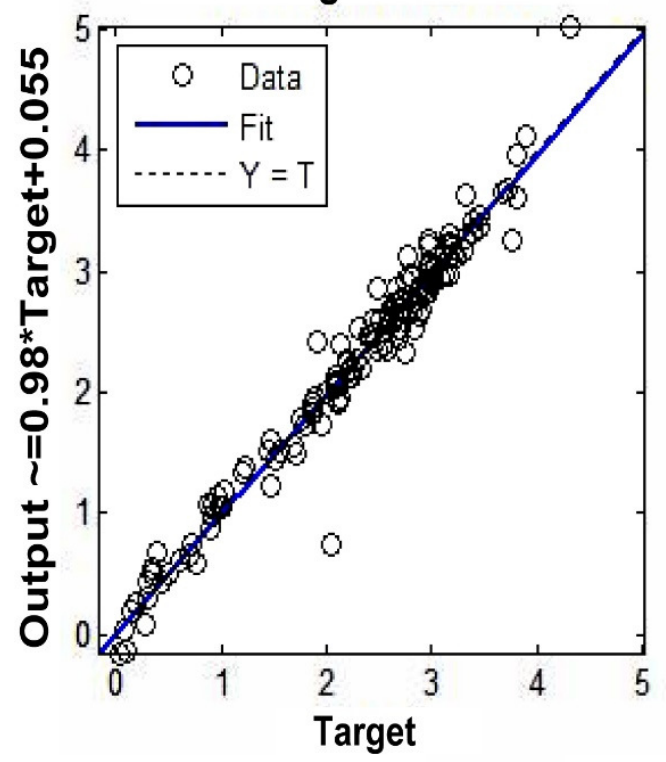

Validation: $\mathrm{R}=0.99184$

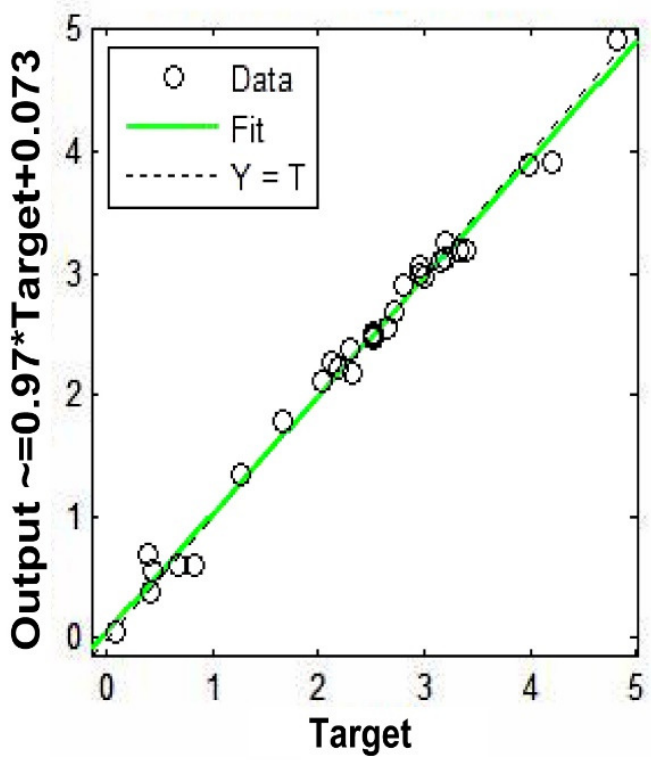

Test: $\mathbf{R}=\mathbf{0 . 9 8 0 4 6}$

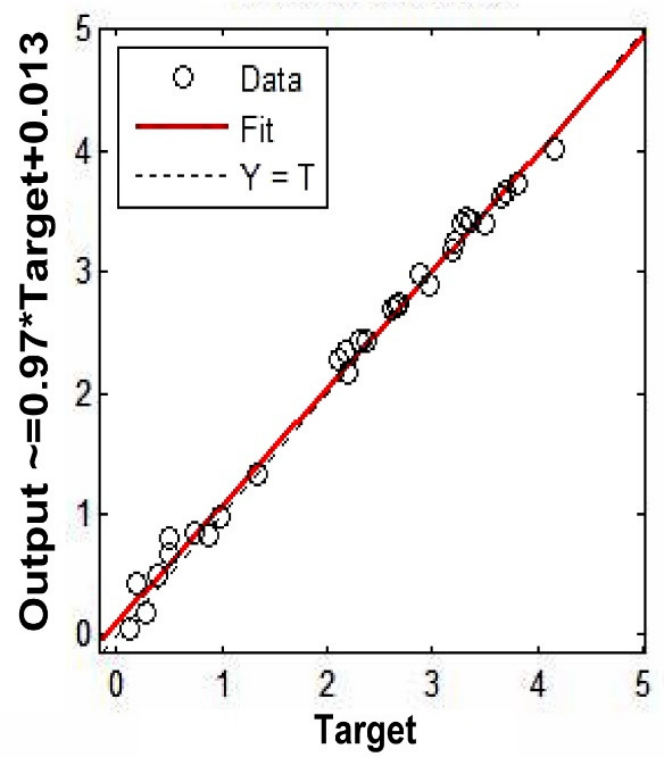

Fig. 8. Regression plots for training, testing and validation of experimental data.

\section{RESULTS AND DISCUSSION}

Comparison between experimental results and predicted values from ANN model was conducted as shown in Table 5. The percentage of error in each verification experiment as individual was calculated for each of Ra and MRR. 
Table 5. Comparison of ANN results with experimental measurements.

\begin{tabular}{|c|c|c|c|c|c|c|}
\hline \multirow{2}{*}{$\begin{array}{c}\text { Experiment } \\
\text { Number }\end{array}$} & \multicolumn{3}{|c|}{ Surface roughness $\mathrm{Ra}(\boldsymbol{\mu m})$} & \multicolumn{3}{|c|}{ Material removal rate $\left(\mathrm{cm}^{3} / \mathrm{min}\right)$} \\
\cline { 2 - 7 } & Exp. & ANN & Error \% & Exp. & ANN & Error \% \\
\hline 1 & 2.2 & 2.1932 & 0.31 & 0.6435 & 0.6350 & 1.32 \\
\hline 2 & 3.35 & 3.0714 & 8.31 & 0.611 & 0.6399 & 4.73 \\
\hline 3 & 4.15 & 4.1631 & 0.32 & 3.1447 & 3.0032 & 4.50 \\
\hline 4 & 3.12 & 3.2519 & 4.23 & 1.158 & 1.0897 & 5.90 \\
\hline 5 & 5.79 & 6.2792 & 8.45 & 0.7125 & 0.7367 & 3.40 \\
\hline 6 & 5.82 & 5.2299 & 10.14 & 1.534 & 1.4849 & 3.20 \\
\hline 7 & 4.88 & 4.8514 & 0.59 & 3.521 & 3.8414 & 9.10 \\
\hline 8 & 4.51 & 4.4284 & 1.81 & 2.185 & 2.5412 & 16.30 \\
\hline 9 & 2.9 & 2.7361 & 5.65 & 2.769 & 2.6527 & 4.20 \\
\hline 10 & 3.78 & 3.7246 & 1.46 & 2.125 & 1.9444 & 8.50 \\
\hline 11 & 6.12 & 5.7838 & 5.49 & 3.612 & 3.7276 & 3.20 \\
\hline
\end{tabular}

The average prediction error of $\mathrm{Ra}=4.2504 \%$

The average prediction error of $\mathrm{MRR}=5.8500 \%$

Total average error of prediction $=5.0502 \%$

For surface roughness, prediction by the ANN model as shown in Fig. 9, it was observed that the correspondence between predicted and experimental results was quite good. The average prediction error between the predicted and experimental results was found to be $4.2504 \%$

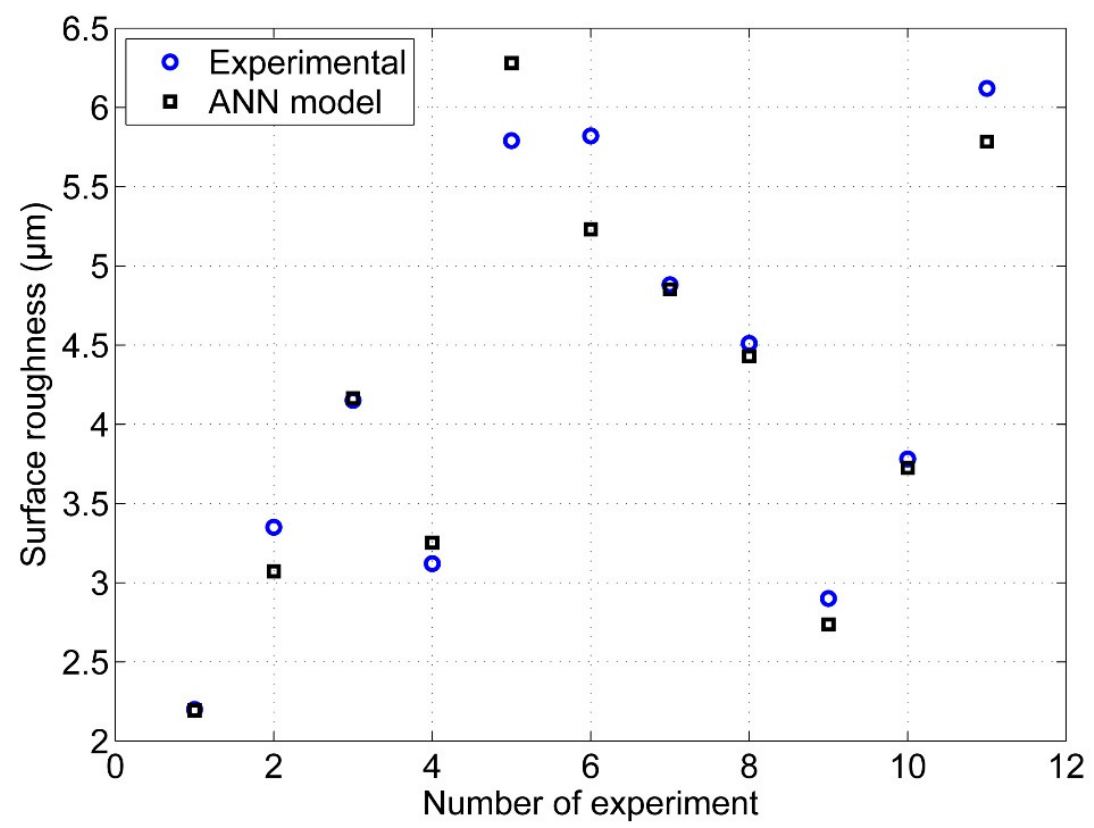

Fig. 9. Comparison between experimental and ANN results of Ra. 
For material removal rate prediction by the ANN model as shown in Fig. 10, it was observed that the correspondence between predicted and experimental results was quite good. The average prediction error between the predicted and experimental results was found to be $5.85 \%$.

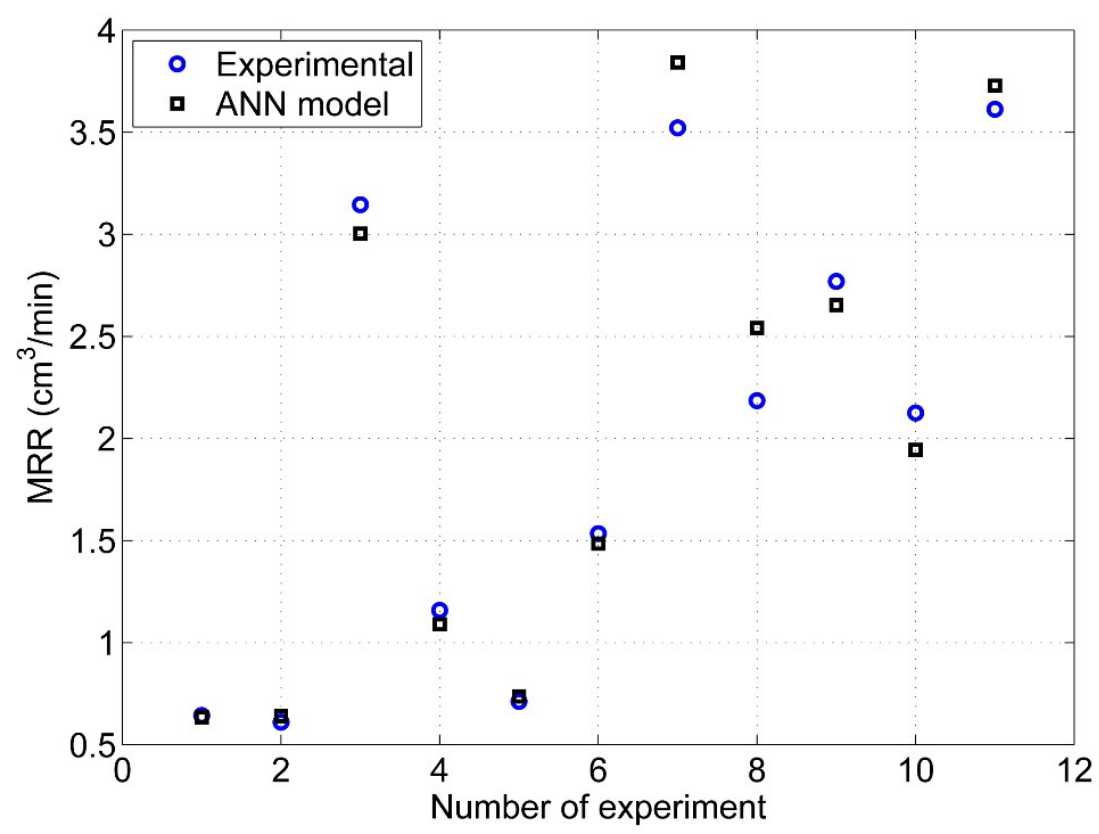

Fig. 10. Comparison between experimental and ANN results of MRR.

\section{CONCLUSIONS}

This work is a step towards investigating the relationship between machining parameters and surface roughness in AWJ machining process. A model of ANN was developed. The architecture of the ANN was feed-forward with back-propagation algorithm. It was found that one hidden layer with 10 neurons can provide a better prediction for surface roughness and material removal rate. The training of developed neural networks can be achieved quickly after 335 epochs.

Comparisons were made after testing their performances on 11 randomly selected test cases. It was found that the total average error of experimental results of MRR and $\mathrm{Ra}$ with predicted values from the developed ANN model was $5.0502 \%$. Welltrained neural network models provide fast, accurate and consistent results making them superior to all other techniques. The artificial neural networks are considered the best data mining in case of data prediction after training these networks well from experimental database. From this, the predictive ANN model can be used for predicting surface roughness and MRR in AWJ process with a higher reliability.

The performance can further be enhanced with large experimental data from full factorial experimentation and considering the additional performance characteristics. 


\section{REFERENCES}

[1] Parikh, P.J. and Lam, S.S., 2009. Parameter estimation for abrasive water jet machining process using neural networks. The International Journal of Advanced Manufacturing Technology, 40(5), pp.497-502.

[2] Summers, D.A., 2003. Waterjetting technology. CRC Press.

[3] Brown, J., 1998. Advanced machining technology handbook. McGraw-Hill.

[4] Inasaki, I., 1998. Principles of abrasive processing. Machining science and technology, 2(1), pp.155-156.

[5] Haykin, S.S., 2001. Neural networks: a comprehensive foundation. Tsinghua University Press.

[6] Russell, S.J. and Norvig, P., 2002. Artificial intelligence: a modern approach (International Edition.

[7] Basheer, I.A. and Hajmeer, M., 2000. Artificial neural networks: fundamentals, computing, design, and application. Journal of microbiological methods, 43(1), pp.3-31.

[8] Barényi, I., Lipták, P. and Vojtovič, S., 2014. Effect of over Tempering at UHSLA Steel ARMOX 500. In Advanced Materials Research (Vol. 875, pp. 1324-1328). Trans Tech Publications.

[9] Iqbal, M.A., Senthil, K., Sharma, P. and Gupta, N.K., 2016. An investigation of the constitutive behavior of Armox 500T steel and armor piercing incendiary projectile material. International Journal of Impact Engineering, 96, pp.146-164.

[10] Romek, D., Ulbrich, D., Selech, J., Włodarczyk, K. and Kowalczyk, J., 2017. Evaluation of wear of machine parts made of Armox 600, Ramor 500 and S355 steel with the use of the rotating bowl unit. Journal of Research and Applications in Agricultural Engineering, 62(2).

[11] https://www.ssab.com/products/brands/armox

[12] http://www.soitaab.com/

[13] Reddy, S., Tirumalaa, D., Gajjelaa, R. and Dasb, R., 2017. ANN and RSM approach for modelling and multi objective optimization of abrasive water jet machining process.

[14] Schwartzentruber, J., Spelt, J.K. and Papini, M., 2017. Prediction of surface roughness in abrasive waterjet trimming of fiber reinforced polymer composites. International Journal of Machine Tools and Manufacture.

[15] Sameh S, Habib A. Modeling of Electrical Discharge Machining of CFRP Material through Artificial Neural Network Technique. Journal of Machinery Manufacturing and Automation. 2014;3:22-31.

[16] Khan, A.R. and Kadirgama, K., 2013. Artificial Intelligent Approach for Machining Titanium Alloy in a Nonconventional Process. International Journal of Mathematical, Computational, Natural and Physical Engineering, 7(1), pp.1098103.

[17] Zain, A.M., Haron, H. and Sharif, S., 2011. Estimation of the minimum machining performance in the abrasive waterjet machining using integrated ANN-SA. Expert Systems with Applications, 38(7), pp.8316-8326. 
[18] Çaydaş, U. and Hasçalık, A., 2008. A study on surface roughness in abrasive waterjet machining process using artificial neural networks and regression analysis method. Journal of materials processing technology, 202(1), pp.574582.

[19] Özel, T. and Karpat, Y., 2005. Predictive modeling of surface roughness and tool wear in hard turning using regression and neural networks. International Journal of Machine Tools and Manufacture, 45(4), pp.467-479..

[20] Zilouchian, A. and Jamshidi, M., 2000. Intelligent control systems using soft computing methodologies. CRC Press, Inc. 